\title{
The Epistemological Contribution of the Transcendental Reduction
}

\author{
Stefano Vincini ${ }^{1,2}$
}

Published online: 3 June 2020

(c) The Author(s) 2020

\begin{abstract}
In order to appreciate the rich implications of the transcendental reduction, one has to distinguish the different contexts where it acquires different meanings. The present paper focuses on a particular epistemological context and clarifies the contribution of the reduction within this context. The contribution consists in the formulation and solution of the problem of exhibiting the evidence supporting the belief in the world's existence. In a nutshell, world-experience grounds the world-belief and world-experience entails a bedrock of experience legitimizing the positing of others. I argue that this contribution is possibly an enduring achievement of Husserl's transcendental philosophy against common objections that are raised against it. I show that both the necessity and the viability of the transcendental reduction are a consequence of the general structure of critical examination. Overall, a picture of Husserl's philosophy emerges that emphasizes embodiment, intersubjectivity, and facticity without giving up the rigor of radical epistemological analysis, aiming at overcoming both naïve pseudo-problems and subtle forms of dogmatism.
\end{abstract}

\section{Introduction}

In this paper, I elucidate the function of the "transcendental reduction" (hereafter, "the reduction") in relation to a specific epistemological problem. Husserl calls the engagement with this problem "radical epistemology" and believes that the reduction is necessary for such epistemology (Hua II, p. 58; Hua VI, pp. 77-78). On certain occasions, he even insists that the reduction is nothing else than remaining mindful of our epistemological problem (Hua II, pp. 5-6; Hua X, p. 346; Hua XXIV, p. 410). However, a correct formulation of the problem requires much phenomenological work. Thus, in order to avoid misconceptions, it will be necessary to provide

Stefano Vincini

stefano.vincini@gmail.com

1 Department of Philosophy, University of Vienna, Vienna, Austria

2 Department of Humanities, Social Sciences, and Cultural Industries, University of Parma, Parma, Italy 
preliminary considerations in Sects. $2-6$. Only in Sects. $7-12$ we will be able to present the problem and Husserl's solution to it.

My goal is twofold. First, at the historical-exegetical level, I seek to show that there is a position on the problem that Husserl corroborated through a variety of texts from around 1906-1936. In this regard, our references to the late Husserl (e.g. Hua VI) will be essential: they will show that the late Husserl endorsed crucial elements of the position we will reconstruct, although in those late years he was not primarily interested in the specific problem we want to tackle. Second, at the systematic level, my goal is to do justice to the position that we will reconstruct from Husserl's texts. In other words, I aim at reviving the philosophical insights that this position contains in contrast to common objections that are raised against it.

\section{Context-Relativity as Methodological Precaution}

We should start by stating a methodological presupposition of our investigation. It consists in Dieter Lohmar's observation that Husserl's terms acquire different meanings in the different "contexts" in which they are employed. According to Lohmar (2012, p. 302), "this flexibility is a merit which is shared by many of the descriptive conceptual tools of phenomenology." However, why is it a good thing that terms may acquire different meanings? Should not the meaning of terms be established at the beginning and remain fixed and clear thereafter?

If we want to pursue a philosophical investigation of certain phenomena, it is necessary to start with words that have conventional meanings. These conventional meanings are not the end, as if they were already adequate to capture the phenomena under investigation. Rather, it is only after having had insights into the phenomena in question that we can use words in a manner that appropriately designates those phenomena. Analogously, when we move from one context of investigation to another, it may be natural to start with words that we have employed in the first context, since they are our most informed way to approach the new phenomena. Yet it would be a mistake to content ourselves with the meanings previously established without a new proper examination. The phenomena of the new context may require significant adjustments and, if we fail to make these adjustments, we may miss the phenomena we are now aiming at. Again, it is only the phenomenological investigation that can gives us the appropriate meanings to be employed in the new context.

Maintaining the same terms helps us track the similarities between phenomena in different contexts and keep in mind the path through which we have gained our insights. Yet, attention to the flexibility of the terms - the context-relativity emphasized by Lohmar - allows us to use the terms in a way that is appropriate to the phenomena of each context. In other words, context-relativity allows us to be true to the phenomena.

The need for context-relativity is most evident in the case of a methodological concept like "transcendental reduction." Indeed, a context is defined at least in part by the direction of investigation, which can be denoted by a major philosophical question. A methodological concept serves the function of carrying us along the desired direction. However, if we improperly maintain the meaning that the concept 
has in another context, it may lead us astray, i.e. prevent us from achieving the insights we seek. In this paper, we identify three main contexts: 1 . Ontological; 2. Metaphysical; 3. Radical-epistemological. The first two contexts will be presented in Sects. 3-5; the third will have to wait until Sect. 7. In view of our methodological precaution, it should not be a surprise if the meaning of the transcendental reduction changes in one or another of these contexts.

\section{Ontology: Clarification of the Meaning of Transcendent Being}

\subsection{Specifying the Question}

The first context we have to consider is the ontological one. This context has a crucial importance for us because the results obtained here constitute essential presuppositions of the radical-epistemological problem we aim at. The major question characterizing the ontological context can be formulated as "What is being?" This formulation is somewhat enigmatic; we must look for clearer formulations.

The first thing to note is that the question does not ask whether something exists. Rather, if you ask the ontological question, it's because you start from the fact that in ordinary life - and in science and philosophy as well-you affirm that certain things exist. However, you want to know what the "existence" or "being" is that you assign to things (for our purposes, we can use "existence" and "being" interchangeably). If you think about it, you realize that it is not clear to you what existence precisely is. Trying to get clear on this point is pursuing ontology.

The ontological question we want to investigate does not concern being in general but, more specifically, what is called "being in itself," "objective existence," or "transcendent reality," assuming that these expressions may refer to the same thing. In fact, the Husserlian question is how we should understand the meaning of these expressions. Specifically, does "transcendent reality" designate something that must have a certain relation to the mind or something that is absolutely mind-independent? For Husserl, the ontological question is a question about "meaning:"

This question about meaning $=$ the question of whether it [the objectivity that exists in itself, transcendent reality] can count as an absolute being or only as intentional being of a specific lawfulness, as unity of a specific manifold of consciousness. (Hua XXXVI, p. 21)

As we shall see, Husserl believes that he can show that one of the horns of this dilemma is "nonsensical" or "countersensical." This presupposes that Husserl can access a fundamental meaning of transcendent existence with which the indicted horn would fatally clash. For Husserl, this fundamental meaning is not the construction of a particular culture, which may be absent in another culture. Rather, the fundamental meaning of transcendent being is the one that is implicit in our life as human perceivers. This life is characterized by the so-called "natural attitude," which is "the attitude of experience," the attitude of the "pre-scientific human being" (Hua XIII, p. 120; 2006, p. 10; translation modified). Thus, we can say that, 
for Husserl, being is something we posit, and ontology has the task of clarifying the meaning of this positing. However, since such meaning must be able to play a fundamental role - that of ruling over sense and nonsense-we have to be more specific and formulate the Husserlian question as follows: what do we posit when we posit transcendent existence in our natural life as human perceivers?

The "general positing" of our natural life is the positing of the world, where the world must be characterized as "the one spatiotemporal actuality to which I belong like all other human beings who are to be found in it and who are related to it as I am" (Hua III/1, p. 61; 1982, pp. 56-57). In natural life, the world is posited as "factually existing" (1982, p. 57). However, the meaning of "existence" and "transcendence" posited in natural life are by no means explicit in the natural attitude. In order to make it explicit, one has to overcome the attitude of the "pre-scientific human being" and carry out a careful philosophical analysis. We shall now recall Husserl's own results in this regard.

\subsection{The Natural Belief in Worldly Transcendence}

To start with, the characterization of the world in Hua III/1 contains only an implicit hint at the category of causality (cf. Hua IV, p. 126; Hua VI, p. 51) but already makes an explicit reference to three elements: singularity, spatiotemporality, and intersubjectivity. That the world must be understood as the one intersubjective spatiotemporality we are familiar with is repeated countless times in texts spanning the entire development of Husserl's transcendental philosophy (Hua I, p. 75; Hua VI, pp. 141-142, 175-176; Hua IX, p. 288; Hua XXIV, p. 203; XXXIV, pp. 250, 334, 436-438). However, the peculiarity of the Husserlian descriptions lies in the insistence that the world is the correlate of perceptual experience (Hua IX, p. 95; Hua $\mathrm{XV}$, pp. 371-372). Surely, the world is not present to us in the way that a perceived particular thing is, but through every particular perception the world presents itself as the spatiotemporal actuality that is the "horizon" of the things perceived (Hua VI, pp. 145-146). Throughout our waking lives, it is one and the same horizonal actuality that is obviously present to us in "flesh and bones" (Hua VIII, p. 250). From Ideas to Crisis, Husserl calls it "the" world.

“"The' world is always there as an actuality” (Hua III/1, p. 61; 1982, p. 57). This means: at each moment, the world satisfies the assumption of being the intersubjective spatiotemporality transcending any previous givenness and available for further verification. There cannot be givenness of the world without this assumption, since the world presents itself as reality, i.e. not as temporary illusion but as verifiable in further experience. Therefore, that I believe in the world's existence means that I assume it to be (in principle) intersubjectively verifiable ad infinitum, or "valid for anyone at any time" (Hua XXXIV, p. 439). This assumption is founded on the link between retention and expectation: retention of concordant experience motivates the expectation of concordant continuation (Hua III/1, p. 102; Hua VIII, p. 51; Hua XXXIX, p. 233).

The reference to the infinity of further verification signifies that the world presents itself as a regulative idea "grown out of experience" (Hua XXXIV, pp. 
435-436) and prescribing the form of synthesis and concordance (Hua XXXV, pp. 276-277). In this way, Husserl is led to define "transcendence" as the characteristic of something that is the correlate of infinite intersubjective verification (Hua I, p. 97). Certainly, transcendence has other meanings in other contexts, but the one that is relevant to our ontological context is only that of infinite intersubjective verification (Hua VIII, p. 495; Hua XVII, pp. 248-258). For example, the "things" of primordial "space"-constituted in the regular correlation of free movement and concordant sensory modalities - are still "immanent transcendencies" and do not possess the objective status of the world (Hua I, p. 136; 1999, p. 106). Take, instead, this table or " $2<3$ " as they are given to me in the natural attitude. They are transcendent phenomena because they are verifiable by infinite possible perceivers and mathematicians. In the natural attitude, my own embodiment appears as a worldly transcendence, i.e. I implicitly take it to be verifiable by others in an infinite process (Hua XIII, pp. 243-244).

Transcendence as infinite intersubjective verification entails the idea of things in themselves (Hua IX, p. 288), i.e. things that exist "whether or not they are perceived" (Hua III/1, p. 104; 1982, p. 110). This idea too belongs to natural experience, and it implies that things that are not perceived could be perceived if someone were in the position to perceive them. Additionally, natural experience implies that no particular consciousness is necessary for a transcendent thing to exist-neither mine, nor yours, nor Mary's, etc. (yet, as we shall see shortly, this is compatible with the idea that at least one intersubjectivity must exist in order for the transcendent thing to exist). Overall, it is a central tenet of Husserl's analysis that natural experience presents the world as "there" in flesh and bones and as a domain of further accessibility ("I and we can"), even if we actualize such accessibility only in minimal parts (Hua XXXIV, pp. 435-436).

Thus, we can formulate the result of Husserl's clarification of the meaning of transcendent being through the following biconditional: something is real if and only if it is verifiable by a community of embodied subjects in an ideally infinite process. This view can be designated as Ontological Embodied Intersubjective Transcendental Idealism (OEITI). OEITI goes far beyond "the attitude of experience" and the "pre-scientific human being" because it requires an in-depth reflective analysis that determines the relation between mind and world. Nonetheless, because transcendental idealism is nothing other than becoming intellectually aware of the implicit reference to infinite intersubjective verification that is intrinsic to natural positing, Husserl can affirm that "transcendental idealism harbors natural realism entirely within itself” (Hua IX, p. 254; 1997, p. 152; cf. Hua I, p. 177; Hua VIII, p. 480).

\subsection{Absolute Mind-Independence as Countersense}

On the basis of the foregoing analysis, one should consider the idea that absolute mind-independence may be a cultural construction. Modern science moved away from certain subjectivity-related aspects of objectivity (values, sensible qualities, etc.). Husserl suggests that the notion of absolute mind-independence comes from misunderstanding this movement as being toward an ideal of absolute 
mind-independence, while it really aimed at the wider sharing of truth between all rational subjects (Hua XXXII, p. 240). What is more, however, Husserl states that absolute mind-independence is a "countersense" or "nonsense" (Hua XXXVI, p. 27; Hua XXXVI, pp. 29-30; Hua XXXVI, p. 78).

To understand this Husserlian statement, it is helpful to think about examples of things that we consider as non-existent, like Santa Claus or the billion dollars in my bank account. There is, unfortunately, no real evidence for their existence. Think about "aether," the all-pervasive material of nineteenth century physics: scientists started considering it as non-existent as a consequence of studies (e.g. the famous Michelson-Morley experiment) that failed to find evidence for it, while alternative theories were gaining increasing empirical support. In general, the point is that-in line with the meaning of being implicit in our natural world-positing-we consider something as non-existent when we assume that no real evidence can ever be given for it. Now, the notion of an absolutely mind-independent existence consists precisely in the notion of something that exists even if no evidence for it can ever be given. Therefore, the idea of this existence amounts to that of something non-existent, i.e. it is a countersense or nonsense.

Zahavi (2017, pp. 71-72) rightly emphasizes that the intersubjectivity to which reality is necessarily related is not just merely possible, but actual. Let us examine whether it makes sense to think that $\mathrm{X}$ exists but is the correlate of merely possible, not actual, intersubjectivity. $X$ is not like the earth before any conscious being inhabited it. This case of existence is in accord with OEITI because the earth's existence before consciousness is part of the existence of a nature governed by stable physical laws for which our present embodied intersubjectivity has actual evidence. In contrast, ex hypothesis, $\mathrm{X}$ is the correlate of possible but not actual experience. Well, $\mathrm{X}$ has the same ontological status as the unicorn I fantasize to be floating outside my window. The unicorn is an object of possible but not actual experience: the experience I would have of looking at him from my window and caressing him, the experience people would have seeing him from the car park, the experience of the competent scientific authorities and security officers that would soon enter the scene, etc. It is precisely because the (potentially infinite) intersubjective experience verifying the existence of the unicorn remains only possible and not actual that the unicorn remains a mere phantasy. To think of something as the correlate of possible, but not actual, experience is still to think of it as non-existent (Hua XXXVI, pp. 78-119).

In this manner, it becomes clear why for Husserl it is so important to stress that absolute mind-independence is "completely alien to the natural way of considering the world;" for what we naturally experience in perception "can never become a countersense" (Hua III/1, p. 120; 1982, p. 129). The difference between natural world-positing and absolute mind-independence can also be emphasized through a correlated distinction: that between the "natural absolutizing of the world" (Hua XXXIV, p. 59) and the "naturalistic absolutizing" (Hua XXXIV, p. 260). The former is merely a consequence of our natural immersion in the world. In presenting us with nothing other than the world and worldly beings, natural experience does not do anything it is not supposed to do. In contrast, naturalistic absolutizing implies the ontological assertion that the transcendent world doesn't have a necessary relation to consciousness. This assertion is a cultural product and does 
something it is not supposed to do: entrap us in countersense (Hua XXXIV, pp. 259-260).

\subsection{Meaning Clarification Doesn't Entail Affirming Transcendent Existence}

OEITI may seem paradoxical. Yet Zahavi (2003, pp. 52-76; 2017, p. 115) reassures us that this position has been held by a number of philosophers such as Kant, Hegel, Heidegger, Merleau-Ponty, Sartre, Pierce, Davidson, Putnam, and even pre-modern thinkers. Husserl states, for instance, that Kant's philosophy is "transcendental" in that it "undertakes to understand the existing world as a structure of sense and validity" (Hua VI, p. 102; 1970, p. 99). Furthermore, Zahavi (2017, pp. 102-103) underlines that OEITI refutes the ontological idea underlying skepticism: the idea of a world beyond experience, the notion that the world of experience could be an illusion even if experience is thought of as the completion of an infinite system of verification.

For our purposes, it is important to understand that whatever we affirm in the ontological context, it does not entail affirming transcendent existence. Of course, insofar as we are ordinary human beings, we keep positing transcendence, but we do not do it within ontological reflection. In ontological reflection, we only pursue an investigation of meaning. Indeed, the OEITI biconditional-if the world exists, then it is the correlate of ideally infinite intersubjective verification, and vice versa-does not entail any existential assertion concerning the world. In other words, clarification is not endorsement: OEITI does not entail affirming that the natural belief in transcendence is true; it only specifies what is believed in such natural belief.

Although ontology does not affirm that worldly subjects exist, it does imply that if the world exists, then intercommunicating worldly subjects must exist. For this reason, ontology ascribes transcendental significance to worldly subjects. Subjects are "worldly" in the sense implicit in the foregoing discussion. This includes: (a) subjects are embodied and occupy a position in the spatiotemporality of the world and also in the causal chain of worldly events; (b) subjects are themselves the correlate of ideally infinite intersubjective verification. Humans are subjects of this kind, and thus Husserl can affirm that "nature is only thinkable as nature in a surrounding world of humans" (Hua XV, p. 371). Along these lines, Husserl affirms that transcendental phenomenology is "the true, philosophically genuine anthropology that explains the absolute meaning of human existence and worldhood" (Hua XXXIV, p. 246).

Another key aspect of Husserl's OEITI is the necessary reference to individual consciousness: the simple, but profound insight that any possible phenomenon, including the world and intersubjectivity, is necessarily a phenomenon for an individual experiencer (Hua XVII, p. 244). The fear that this consideration entails a slip into solipsism is irrational and reveals a failure to understand the intentional nature of consciousness (Hua I, pp. 176-177; Hua XVII, p. 258; Zahavi 2003, p. 114). 


\section{Metaphysics: The Search for the "Fundamental Fact"}

In the previous section, we presented OEITI because it is presupposed in the radicalepistemological problem we will introduce in Sect. 7. In this section, we familiarize ourselves with a Husserlian metaphysical context because we will need to have this context clear in our minds in order to be able to separate it from the radical-epistemological context.

In Husserl's transcendental philosophy, metaphysics evaluates certain "interpretations of empirical actuality" (Hua XXXVI, p. 22). The metaphysician acknowledges empirical actuality and seeks a philosophical understanding of it. To the "reality of experience" certainly belongs the world posited by the natural attitude as "factually existing," but also single physical things and people. Husserl tells us that the metaphysician searches for "the absolute," for "actuality in the ultimate meaning." The absolute would be a "fundamental fact" (Urtatsache) upon which the other actualities considered by the metaphysician depend but which does not depend in turn on a fact different from itself. The reference to "meaning" suggests that actuality must be considered in light of a previous ontological analysis.

The result of Husserl's metaphysical search is that the "fundamental fact" (Hua $\mathrm{XV}$, p. 366) is the coexistence of my human body, intersubjectivity, and the world. None of the elements of this triad can exist without the other because none can verify itself without the other. The fact of this triad is "the absolute" (Hua XV, p. 370) in the sense that any other fact implies the triad for its verifiability, whereas the triad does not imply any factual reality different from itself for its own (Hua XXXVI, p. 27). Although it remains true that any reality is in principle a phenomenon for each individual experiencer, it would be wrong to think that a single individual consciousness could function as the absolute upon which transcendent realities depend. For these realities require an actual plurality of subjects that can in principle verify them ad infinitum.

In this context, Husserl describes transcendental idealism as a "synthesis of the natural and the transcendental attitude" (Hua XXXIV, pp. 16-17) because it posits the world, as the natural attitude does, but is also aware of the mind-world correlation. Thus, following Lohmar's methodological suggestion, we should distinguish OEITI, a mere ontological clarification, from MEITI, the metaphysical assertion of the existence of intersubjectivity and world as transcendentally related. Formally, we can describe the distinction between OEITI and MEITI by saying that the former is a mere biconditional whereas the latter entails the biconditional plus an existential statement.

That metaphysics entails a previous ontological analysis is sometimes expressed though the idea that ontology "has metaphysical implications" (Zahavi 2017). Yet, as emphasized in 3.4, it would be a mistake to think that clarifying the meaning of existence coincides with affirming existence. We must never forget Drummond's (2019, p. 270) warning: "having implications for metaphysics is not the same as taking a positive stance within metaphysics."

In this connection, we should linger a moment on the kind of reflective endorsement that metaphysics gives to the natural positing of actuality. The metaphysician 
grants validity to the natural assumption that considers factual events as correlates of an ideally infinite intersubjective verification. For example, natural experience presents us with the lived experiences of humans (perceptions, recollections, volitions, etc.). These experiences are "psychological" facts in the sense that they belong to the domain investigated by psychology, a science carried out within the natural attitude. In Husserl's texts, the term "psychology" does not designate an investigation of the contingent, or empirical, features of lived experience; there is, in fact, an a priori psychology (Hua IX; Hua XVII, p. 261). Rather, psychology is the investigation of lived experiences insofar as they belong to a worldly subject, i.e. a transcendent being (Hua XVII, pp. 237-238; Hua VI, p. 182). The "psyche" is the nexus of lived experiences belonging to a worldly being (Hua V, pp. 145, 158). However, the meaning of worldly transcendence is not transparent in psychology, since psychology remains in the natural attitude. The metaphysician knows that such meaning consists in the assumption of infinite intersubjective verifiability and grants validity to this assumption. Therefore, that the metaphysician acknowledges lived experiences as worldly facts means that she knowingly assumes that they are the correlate of ideally infinite intersubjective verification.

\section{The Reduction in Ontological and Metaphysical Contexts}

Across all contexts examined in this paper, the transcendental epoché and reduction are the negative and positive sides, respectively, of one and the same methodological operation. In this short but important section, I indicate the meaning that epoché and reduction have in both ontological and metaphysical contexts.

The natural attitude is not aware of the necessary relation of the world to consciousness. This unawareness is what Husserl calls "naivete" or "forgetfulness." It is "the unawareness of the transcendental relativity of the world" (Hua XXXIV, p. 59). In order to achieve the ontological clarification of the world's meaning (OEITI), a twofold operation is required: (1) the epoché as suspension of natural naivete, i.e. the suspension of our unawareness of the mind-world correlation (Hua XXVII, p. 173; Hua XXXIV, pp. 59-61); and (2) the reduction as "thematic reorientation" from the world experienced one-sidedly to the world "in its concretion" as correlated with its modes of givenness (Zahavi 2017, pp. 59-60). The same twofold operation is needed in the metaphysical context: in order to affirm MEITI, one needs to suspend natural naivete (epoché) and to have a positive awareness of the mind-world correlation (reduction).

\section{The Non-circularity Requirement of Critical Examination}

The problem in view of which we pursued the foregoing discussion is a specific epistemological problem. To this specific problem one has to apply considerations that have a general epistemological scope. Hence the last step before introducing our problem will be to elucidate these general epistemological considerations. 
The first general remark concerns the distinction between knowing and grounding. Knowing (Erkennen) designates the process of the formation of knowledge. At the center of this process Husserl puts the fulfillment (and disappointment) of "empty intentions," or expectations. Knowing can be described as a "game of induction and fulfillment" (Hua XXXII, p. 139), where "induction" is taken in an unusually wide sense to indicate all kinds of expectations originating in past experience or thought activity: expectations can then be verified or falsified by experience. Heidegger (1962, p. 95) describes this "possibility of the most primordial kind of knowing" as the hermeneutic circle. Knowing is the process of "working out [...] fore-structures" (expectations) in relation to the "things themselves" as they present themselves in experience. Importantly, knowing includes verification as a vital part: a claim to knowledge that is only partially fulfilled must be able to be verified in further experience. Verification (or "confirmation") is this process of realizing a more complete fulfillment.

Grounding (Begründung) is a reflective-epistemological kind of knowing. It occurs when I already have at my disposal a belief understood as an item of knowledge and I exercise critical examination. Specifically, grounding the belief in $\mathrm{X}$ is putting it in relation with the evidence for X. For example, I can ground my belief in the existence of a table in my office by recalling my perceptions of it, recollecting a conversation I had about my office's furniture with a colleague, and possibly going to my office and seeing the table, thus adding an evidence having the character of "original givenness" to the system of evidence grounding my belief (Hua XXIV, p. 120; Hua XXXVI, p. 118). Analogously, I can ground my belief in $2<3$ by reproducing the clear insight that $2<3$ and recognizing that the former belief is epistemically grounded in the latter insight. These procedures relate a belief in $\mathrm{X}$ with experiences presenting $X$; thus, they are different from merely repeating to myself that the table exists or that $2<3$. This kind of repetition may be an effective method of reassuring myself about a belief of mine, but it does not count as grounding.

Critical examination involves a relation usually discussed in logic. With regard to the fallacy of circular reasoning, logic textbooks commonly provide the example "I know that God exists because the Bible says so and God wrote the Bible." We can imagine a person performing this reasoning as being asked to justify her belief and we can suppose that her unawareness of the ineffectiveness of her reasoning is due to her lack of training in critical thinking, though nowhere the truth of her belief is in question in these considerations. In general, positing $\mathrm{X}$ in order to exhibit the evidence for one's belief in X cannot work because it employs the ungrounded affirmation of the belief in X (a mere repetition) as ground or evidence for one's belief. We can formulate the general non-circularity requirement of critical examination as follows:

An attempt to exhibit the evidence for a belief must not reaffirm the belief in question as a presupposition.

Husserl formulates the requirement in general terms (Hua II, p. 33; Hua VIII, p. 66; Hua IX, p. 291; Hua XXXIV, p. 437), though these formulations are not entirely unaffected by the particular problem that occasions them. In any case, Husserl gives us a precious description of what we commonly do when 
someone doubts one of our judgments or when we ourselves sense the need for critical reflection and, in any case, wish to re-examine our judgment "without prejudice." "Without prejudice!" does not mean that we ourselves have come to vacillate about it or that we have relinquished our judgment. We are perhaps quite firmly convinced; we judge subsequently as before. And yet, we examine it without prejudice. And in this case too, it means: For our re-consideration, we disengage the judgment: What has been judged we do not accept as true in the reconsideration, we make no use at all of that which was claimed to be true. If we forget that, if we accidentally or by means of some verbal phrase fall back into the original attitude, and if we make total or partial use of the content of the original assertion during the critical reflection and process of justification, then we will fall into the familiar mistake of the circulus vitiosus. (Hua XIII, p. 152; 2006, p. 43; my emphasis)

For Husserl, critical examination has no arbitrary limits. Philosophy is guided by the ideal of self-responsibility, which entails working toward the awareness of what evidence the philosopher really possesses for her most significant beliefs. Thus, if we seek to realize this ideal, we must sooner or later submit to critical examination the world-belief, which is the ground of all sciences (Hua XXVII, pp. 169-170). For Husserl, resisting the critical examination of one's own beliefs and the commitment to circular forms of reaffirmation is the quintessence of dogmatism (Hua XXIV, $\mathrm{p}$. 188; Hua VI, p. 192).

\section{The Epistemological Motivation of the Transcendental Reduction}

We finally arrive at the specific problem we have been preparing for, now armed with the necessary equipment to understand it. This is the problem that requires the transcendental reduction in a specific sense. It is usually discussed as its epistemological motivation (Lohmar 2012; Rinofner-Kreidl 2004). The problem is grounding the world-belief. Solving it requires ascertaining a domain of evidence without presupposing the world-belief; otherwise we would merely reaffirm what we are supposed to ground. The epoché consists in the compliance with the non-circularity requirement in the case of the world-belief.

As radical epistemologists, we want to exhibit the evidence for the world-belief. The non-circularity requirement tells us that, in order to do so, we need the epoché in the sense of world-belief suspension (Hua III/1, p. 65). To perform the epoché is to "no longer keep in effect [...] the natural believing in existence involved in experiencing the world" (Hua I, p. 59; 1999, pp. 19-20) and to "refrain from taking any position on the being or non being of the world" (Hua VI, p. 78; 1970, p. 77). The reduction is the exhibition of evidence based on this epoché.

In order to fully appreciate the problem's demand, we also need to understand that world-belief grounding coincides with clarifying the possibility of transcendent knowledge. In this regard, the first observation is that "the task of the critique of knowledge is to clarify [...] the legitimacy of its claim to validity" (Hua II, p. 32; 1995, p. 25) and that the legitimacy of knowledge's claim to validity is 
its groundedness. Then, we should observe that it is "objective" or "transcendent" knowledge that we refer to when we question "the possibility of knowledge" (Hua II, pp. 33-36; Hua XXXVI, p. 41). Since it presupposes intersubjectivity, transcendent knowledge is worldly knowledge. Therefore, clarifying the possibility of transcendent knowledge - the legitimacy of its claim to validity — coincides with grounding worldly knowledge in general, i.e. with world-belief grounding.

In this way, the world-belief grounding problem leads us to focus on the distinction between transcendent and immanent phenomena, which for Husserl is the "most radical of all ontological distinctions" (Hua III/1, p. 159; 1982, p. 171). Here the concept of transcendence relevant to the main contexts of this paper is the one based on the notion of natural positing. A transcendent phenomenon is one that implies the world's further intersubjective verifiability. Specifically, it requires that the ideally infinite future course of my experience includes a synthesis of concordance though which "the" world (this intersubjective spatiotemporality) verifies itself. Conversely, immanent phenomena must be defined as phenomena that do not entail this anticipation; they are what they are, phenomena inscribed in delimited segments of consciousness, independently of whether the future course of my experience presents that synthesis of concordance or not.

Now, if the problem is to ground the belief in the transcendent world and the epistemologist starts considering transcendent phenomena, then she is falling back into the attitude of transcendent knowledge: by considering transcendent realities one gets to know more about the world but not about how knowledge of the world is possible. Yet, when one wants to understand how one's own world-belief is epistemically grounded, one wants to understand how one's own world-belief, taken as a phenomenon of consciousness, stands in a relation with presenting experiences of one's own that ground it. In short, when we investigate the possibility of transcendent knowledge, we do not want to know more about the world; we want to know about the epistemic legitimacy of a conscious belief.

Therefore, if the epistemologist wants to clarify the epistemic ground of the world-belief but examines transcendencies, then she commits not just vicious circularity but also the infamous metabasis eis allo genos, a nonsensical shift of the domain of investigation (Hua II, pp. 5-6). In a way that is incompatible with the proper meaning of her investigation, she shifts from the domain of immanent-epistemological reflection to the domain of transcendent knowledge. As Rinofner-Kreidl (2004, pp. 44-51) puts it, transcendent knowing and epistemological grounding are "different types of question;" epistemological analysis "requires a [...] shift of the object domain."

\section{Seven Classes of Textual Evidence for the Epistemological Motivation}

Husserl's transcendental reduction, understood as reflection under world-belief suspension, is motivated by the problem of grounding the world-belief, since this problem requires avoiding circular reaffirmation and nonsensical domain-shifting. We can organize the evidence for this claim into seven classes of textual references. 
The first class includes all passages affirming the necessity of the epoche for grounding the world-belief or the positing of transcendence (Hua II, p. 58; Hua III/1, p. LVI; Hua VIII, p. 476; Hua XXIV, pp. 204-214; Hua XXVII, pp. 169-170; Hua XXXIV, pp. 16-17).

The second class denotes passages in which Husserl formulates the epistemological motivation of the reduction in an explicit and general manner, i.e. in terms equivalent to the ones we used in Sect. 7 (Hua II, pp. 5-6; Hua X, p. 346; Hua XXIV, p. 188).

The third class is composed of passages that present the motivation in an explicit and specific manner, i.e. by specifying the domain where one has to avoid domainshifting circularity. This is the domain of cognitive processes, because the evidence for a belief is ultimately to be sought in presenting experiences (Berghofer 2019). As shown in Sect. 4, when cognitive life is taken to belong to an embodied subject existing in the world, Husserl calls it "psyche." The specific epistemological nonsense the epoché allows us to avoid is identifying a psychological phenomenonwhich is a worldly reality, a transcendency - as ground for the world-belief. Husserl designates this nonsense as "psychologism" or "transcendental psychologism." The passages of the third class motivate the reduction as the demand that we shun psychologistic circularity (Hua II, p. 39; Hua VIII, pp. 70-73; Hua IX, p. 291; Hua XVII, pp. 259-260; Hua XXIV, pp. 211-212).

Transcendental philosophy consists in a "constellation" of problems, questions, or tasks, where the plural is often emphasized by Husserl (Hua I, p. 116; Hua XVII, p. 260; Hua XXXII, p. 7). World-belief grounding certainly belongs to such a constellation. Thus, the fourth class of evidence is made up of Husserl's formulations of the transcendental-epistemological task of clarifying how consciousness comes to posit the world in an epistemically grounded manner. For example, the task is to describe

how it [consciousness] [...] manages in its immanence that something which manifests itself can present itself as something existing in itself, and not only as something meant but as something authenticated [Ausweisendes] in concordant experience (Hua IX, p. 289; 1997, p. 169; my emphasis).

In this passage, like all other equivalent passages, framing the problem within the domain of the immanence of consciousness constitutes an implicit reference to the necessity of avoiding circular domain-shifting: only if consciousness is examined as a purely immanent phenomenon is the identification of the evidence for the positing of transcendence sheltered from psychologism (Hua II, pp. 7-35; Hua II, pp. 46-56; Hua VII, pp. 247-248; Hua X, p. 345; Hua XVII, pp. 237-238; Hua XXIV, p. 156; Hua XXXIV, pp. 243-250). Notably, a subclass within the fourth class comprises the passages that formulate the transcendental-epistemological task through a positive reference to Descartes. Indeed, according to Husserl, the task originated in Descartes when he pointed to the necessity of a radical epoché for a reflection on one's own conscious life aimed at unveiling the epistemic ground of the natural positing of transcendence (Hua I, p. 74; Hua VI, pp. 77-78; Hua VI, p. 100).

The fifth class includes all passages stating that, although the subjectivity disclosed in the transcendental epoché is actual-indeed, an indubitable fact (Hua I, 
p. 62; Hua V, p. 146) - this subjectivity is something that "exists whether or not the world exists," an actuality that does not depend on the world's existence (Hua I, p. 64, p. 69; 1999, p. 30; Hua III/2, pp. 589-590; Hua VII, pp. 254-259; Hua VIII, pp. 76-77; Hua XLI, pp. 352-356). As Husserl puts it in Crisis, when the phenomenologist reflects on transcendental subjectivity, she has no interest in the world's existence or non-existence (Hua VI, pp. 154-155, 178-182). Statements of this kind make it clear that the epoché does not function in Husserl only in the context of an ontological exploration of the world's meaning, or in a metaphysical context that assumes the validity of "empirical actuality" and seeks what fundamental fact must be there to support it. Rather, such statements become intelligible only if one admits the presence in Husserl of a different philosophical project as well. This is a project-world-belief grounding — that is defined precisely by the constraint of "refraining from taking any position on the being or non-being of the world." In this project, applying to an actual subjectivity categories such as "worldliness" or "unworldliness," "embodiment" or "disembodiment" would be nonsensical because it would imply taking a position "on the being or non-being of the world" and thus would fall outside the domain of meaning inaugurated by the project. In this connection, we should note that when the epistemologist grounds her own world-belief, she takes her own world-belief and the evidence supporting it as actual. Nonetheless, she can affirm that such evidence supports her belief because it is an evidence of the kind that supports the kind of belief which her belief instantiates. This is the reason why world-belief grounding must also be performed at the level of structural necessities (Husserl's "eidetic" level).

The sixth class comprises passages affirming that the epoché is the suspension of the natural world-belief that arises within, and belongs to, the domain of "natural world-experience" or "natural givenness" (Hua I, p. 72; Hua III/1, p. 66, Hua VI, p. 153, and Hua XIII, p. 174; Hua XXXIV, pp. 435-436). For example, in Hua IX (p. 90), Husserl characterizes the world-belief as a natural interest in the confirmation of the at any time pre-delineated horizon of experience; then he describes the epoché as becoming disinterested in this sense. Passages of this kind exclude the possibility that the epoché may be understood as coinciding with the suspension of a positing of absolute mind-independence. If this possibility had textual support, one might think that, for Husserl, the epoché had only the ontological or metaphysical function of suspending a nonsensical positing to turn our attention to the true positing. The passages of the sixth class eliminate such a possibility. They make it clear that the suspension of a positing of absolute mind-independence is only a consequence of the fact that, when natural world-positing is suspended, all "philosophical" worldpositings-be they "legitimate or perverse" — are suspended (Hua VII, pp. 254-255; 1974 , p. 28). Therefore, we must acknowledge that the suspension of natural worldpositing does not have the function of orienting us toward a "truer" positing. Rather, it has the function of allowing us to exhibit the evidence for such positing without running into nonsensical circularity.

The seventh class consists of texts that explore "pure phenomenology" as a discipline investigating the domain of phenomena disclosed by world-belief suspension while hinting at the epistemological function of this domain (Hua III/1, pp. 68-69; Hua XIII, pp. 150-151). Indeed, it should be said that the domain of immanent 
phenomena can be explored as a field that is of interest in itself. Yet one can always come back to the original motivation that led to opening the field in the first place.

Lastly, we should stress a subclass within the third class (passages identifying the motivation of the reduction in the requirement of eluding the transcendental-psychologistic circle). The passages of this subclass assert that Descartes' fundamental mistake was to consider subjectivity as a worldly being. Descartes couldn't but fail in the very project of grounding he inaugurated, because he circularly posited the world in his very conception of subjectivity. These passages qualify the reduction as an essentially anti-Cartesian move (Hua VI, p. 80, 83-84; Hua XVII, pp. 235-236; Hua XXIV, p. 216). ${ }^{1}$

\section{The Viability of World-Belief Suspension in Light of the Structure of Critical Examination}

At this point, one may want to object that the required epoché is impossible because the world-belief cannot be suspended at will. This kind of objection reveals a confusion concerning the idea of world-belief suspension.

Recall the long quote in Sect. 6 about ordinary self-examination. When I examine an opinion of mine, critical examination-by itself_-does not change in the least the fact that I have that opinion. I can change my opinion as a consequence of the examination, but this is not always necessary, and in any case it does not belong to the phenomenon of critical examination, i.e. the uncovering of a belief's evidential status.

Imagine that, on a quiet Viennese morning, I suddenly ask you to tell me why you are justified in assuming that the croissant you are about to eat has not been poisoned by the baker. You know about my epistemological interests, so you kindly satisfy my request. There are things that come to your mind: (1) you have shopped at the bakery for a long time and have always been fine; (2) the baker always seemed to be a good person; (3) it is not a great business strategy to poison one's own products, not to mention the risk of having to pay the legal consequences; etc. None of the reasons you mention — which are, no doubt, good and valid reasons-presuppose the croissant's edibility. Without having to think about it, you steered away from considerations presupposing the belief you were supposed to ground. Husserl calls this a "self-evident requirement" (Hua IX, p. 291). While you were telling me your reasons, however, you were also enjoying your croissant-which shows that at no point did you stop believing in the croissant's edibility. One might then wonder: how is it possible that you maintained the belief and, at the same, you suspended it to ground it with evidence?

\footnotetext{
${ }^{1}$ Another subclass within the third class includes passages where Husserl emphasizes that a "psychological" interpretation of subjectivity constitutes the unbridgeable gap that separates Kant from grasping the radical-epistemological task (Hua III/1, p. 133; Hua VI, pp. 102-105, p. 423; Hua VII, pp. 357-378; Hua XXIV, p. 339).
} 
Well, the first observation should be that you can actually do it in many cases without much difficulty. Think about ordinary or scientific beliefs that we do not normally question because we take them to be obvious, but for which we do have reasons (like our croissant example): we are capable of calling to mind non-circular reasons for accepting those beliefs without ceasing to hold them as beliefs (Hua XIII, p. 152). Second, the paradox is solved if one realizes that critical examination is a phenomenon of "I-splitting" (Hua XXXIV, p. 59): I have an opinion, but, if I engage in critical reflection, I inaugurate a novel domain of intentionality characterized by the fact that the things I can find in it do not presuppose the opinion's validity. While I remain what I am, a person with such and such convictions, I take a de-centered position that allows me to identify the evidence I possess for such convictions.

I-splitting should be seen as a relatively ordinary possibility for the kind of mind that human beings have. Each of us often inhabits different domains of intentional life at the same time. For example, in teaching, I inhabit the level of knowledge I deem my students to have; in reading a phantasy book, I take as valid the rules of the phantasy world; in making a moral choice, I do not rely on my particular interests but on the point of view of what is good "for any rational being" (Hua XXXVII, p. 235 ); etc. Critical examination is just another regulated domain of my intentional activities.

World-belief grounding is a project of critical examination. For Husserl, it is obvious that world-experience and world-belief go on as before while I perform the epoché and that they cannot be suspended at will (Hua I, p. 59). Though I still posit the world insofar as a "lower" nucleus of myself still lives a natural life (Hua I, pp. 60-61; Hua VI, p. 155; Hua XXXIV, p. 59), to the extent that I make this lower life the object of my reflection and engage in world-belief grounding, I establish a different domain of givenness: I'm intentionally directed at phenomena whose givenness does not presuppose the world-validity.

We cannot ignore all the expressions that Husserl continuously employs to signal that the epoche is a project-relative operation: I suspend the world-belief "as radically meditating philosopher," "as reflecting philosophically," "qua philosophizing Ego" (Hua I, pp. 59-73; 1999, pp. 18-35) or "as one who is philosophizing" (Hua VI, p. 79; 1970, p. 77). Therefore, if one objects that the world-belief of natural life cannot be suspended at will, the reply must be:

The main point is not whether the judgment [transcendent positing] is rescinded in earnest, really suspended in the ordinary sense, but only whether it is deactivated within the entire sphere of epistemological investigation (Hua XXIV, p. 214; 2008, p. 209; cf. Hua XXXIV, pp. 246-249).

\section{Conditions of Meaningfulness}

The radicalism of the question of the possibility of transcendent knowledge is evinced in the observation that world-belief grounding implies grounding intersubjectivity. If there were no epistemic ground for positing others, there would be no 
epistemic ground for positing an intersubjective world (Hua I, pp. 124-175; Hua XV, pp. XIX-XX).

Suspending the world-positing entails suspending the positing of others (Hua I, pp. 58-59; Hua I, p. 176; Hua VI, pp. 187-189; Hua XXIV, pp. 212-213), my body, and my psyche (Hua VI, pp. 82-84, p. 187; Hua VIII, p. 74; Hua XXXIV, p. 251; Hua XXXIX, p. 42) because all of these are worldly transcendencies. However, identifying the evidence for positing others requires a special "deepening of the transcendental reduction" (Lohmar 2012, p. 300) called "primordial reduction." It consists in identifying a domain of presenting experiences in my natural life that does not presuppose the positing of others. This domain is a fundamental stratum of pre-reflective life presenting unities of manifestations in an original manner. For example, the "thing" is a unity of manifestations regularly correlated to my free movements and concordant sensory modalities (I can touch the back of the "thing" or see it if I turn around it). Husserl variously designates this domain as "primordial world," "arche-ego," or "sphere of ownness." Only in the concordant interconnections of presenting experience in the sphere of ownness can we uncover the rational legitimacy for positing others, and so also worldly phenomena transcending such a sphere (Hua VIII, pp. 434-439).

Overall, our textual references demonstrate that Husserl conceived of the possibility of world-belief grounding by thinking through the conditions in which it can be meaningfully pursued. Without world-belief suspension, there can only be a psychologistic discourse on lived experience that circularly presupposes the worldbelief and nonsensically shifts the presumed domain of investigation.

For Husserl, there is no doubt that there is an epistemic ground for the worldbelief (Hua VII, pp. 245-247; Hua XVII, p. 241; Hua XXXIV, p. 247). As shown by the references of the fourth class (formulations of the transcendental-epistemological task), the radical epistemologist presupposes that the world-belief is epistemically grounded and her task is only to clarify how it is so (see also Hua XXXIX, pp. 234-235 and Hua II, pp. 36-37). Indeed, the specificity of grounding in the more general domain of critical examination is that grounding presupposes the existence of the rationally motivating evidence beforehand and only seeks to exhibit it.

\section{The Solution}

\subsection{A First Sketch}

The path to the correct formulation of the radical-epistemological problem is "incomparably longer" than the path from the problem to the solution (Hua XXIV, p. 340). The present section is devoted to the solution, but we will still have to counter objections against the very possibility of formulating the problem in a coherent manner.

The first step of the solution is to grasp a general "demand of reason" as it emerges from perceptual life, ordinary knowledge, and scientific practices (Hua IV, p. 223). Reason demands that we acknowledge "the most original right" of "induction" from concordant experience to a domain transcending it (Hua XXXII, pp. 
138-139). Having had a concordant experience of tables and of the table in my office, I legitimately expect to see it from the opposite side if I walk around it; if a person has shown herself to be morally good on many different occasions for a long time, I know that I am more justified in trusting her than a person I have just met; the repeatability of experiments is considered a primary requirement in science; etc. These are all forms of concordant experience that legitimate the positing of realities transcending the grounding experience.

Husserl provides us with a solution to world-belief grounding in all the passages in which he shows how world-experience grounds the world-belief (Hua III/1, p. 43, 326; Hua VII, pp. 244-245; Hua VIII, p. 434; Hua XIII, pp. 136-137; Hua XX, p. 328; Hua XXXIX, pp. 234-235). It is the concordant perceptual presence of the world in flesh and bones over time-i.e. the continual confirmation of the expectation of experiencing the same world in an original manner-that grounds the worldbelief, i.e. the assumption that the world is the correlate of infinite intersubjective verification. Since intersubjective verification, like any phenomenon, is a phenomenon for my individual consciousness ( 3.4 above), my world-belief consists in the assumption that the future course of experience will continue to attest the same spatiotemporality that has been intersubjectively certified so far (Hua XXXIX, p. 266). In other words, my natural assumption excludes in an unshakable manner the pure possibility of "world-annihilation" (Hua III/1, p. 104; 1982, p. 110) i.e. a future course of experience presenting a "spatiotemporality" occupied exclusively and chaotically by mere transient sensory unities ad infinitum. The anticipation of future verification is legitimated through "the most original right" of induction from the concordance of world-experience so far.

\subsection{Safeguarding the Solution}

In order to safeguard this solution, one must endorse the so-called "East Coast interpretation" of the noema and understand it correctly. "The meant world purely as meant" is the world "abstractly considered-apart from the positing of the natural attitude" (Drummond 1990, p. 113). This means that I do not assume-as I always implicitly do in the natural attitude - that the experienced world is the correlate of possibly infinite future corroboration.

In a given experience, the world with all its transcendent realities is posited as verifiable in further experience. I consider the world precisely as posited as verifiable, but it is not my concern whether it will actually be verified or not. In other words, I take the transcendence that is meant precisely as it is meant in the given experience, i.e. "emptily," without taking a side with respect to its actual verification in further experience. Therefore, the meant world purely as meant belongs to the experience in question: it is not something supposed to transcend it by corroborating itself in further experience. While in natural life I expect the world's further corroboration, in reflection I do not reproduce this interest in future verifiability. The meant purely as meant is what it is within the boundaries of the experience in question, which I reflectively examine. 
Thus, in order to safeguard the world-belief grounding project, we have been led to the affirmation that, under the performance of world-belief suspension, the world appears to the reflecting "I" as a cogitatum qua cogitatum, an apodictic component of the transcendental sphere. This is precisely what Husserl affirms in an unequivocal manner: Hua I, p. 75; Hua I, pp. 58-75; Hua VI, pp. 78-79; Hua V, pp. 145-146 (see also Hua IX, pp. 282-294 and Hua VI, pp. 178-182).

\subsection{Reformulating the Solution and the Intruder Objection}

Husserl also presents his solution to world-belief grounding in terms of the distinction between the world of experience and the world as "truly and really being:"

True being (and in particular the true being of nature) is not a second being next to mere intentional being. This is correct, although we must distinguish between nature as intended by us now precisely in this manner and incompletely, through presumptions, and nature in itself. (Hua XXXV, pp. 276-277; cf. Hua XXXIX, p. 266)

The world-belief is the implicit presumption that the world of experience is identical with the world of ultimate verification. In radical-epistemological reflection we (each for herself or himself) (1) consider the world as presumptively intended without endorsing such presumption; (2) recognize that the world presumptively intended has been given in concordant and original (evidential) manner in the course of experience so far; and thus (3) acknowledge that the presumption is rationally legitimate-world-belief grounding achieved.

The most common objections to Husserl's world-belief grounding concern (1), i.e. the very possibility of a consistent formulation of the problem. Typically, the objections suggest that there is something that the radical epistemologist allows to break in from the natural attitude: the usual intruders are things like the body, language, intersubjectivity, tradition, etc. The question, however, is whether the objector is not simply very resistant to examining these phenomena from the point of view of world-belief suspension. Why should I not consider the body, or language, precisely as experienced? When I undertake transcendental reflection, why should I have an irresistible tendency to assume that the body, or language, is infinitely verifiable in further experience? If one leaves prejudices behind, it is possible to realize that all these alleged intruders contribute to transcendental constitution only to the extent to which they play a role in the domain of "phenomena." There can be no contribution to meaning-constitution if not from the immanence of consciousness.

\subsection{Deepening the Solution}

In the foregoing, Husserl's solution was given a general formulation. Yet worldbelief grounding depends on the legitimacy of positing others. Thus, Husserl included in his solution the non-circular clarification of the epistemic ground of intersubjectivity (Hua VIII, pp. 434-439). 
Although we do not have an actual non-intersubjective experience of spatiotemporality available for intuitive reflection, each of us can identify a non-intersubjective domain of experience and meaning that is necessary for world-experience. I could not experience the objective world if I did not experience: (1) my active and affected "animate organism;" (2) "things" as "belonging to an infinite system of my potentialities," e.g. those of perceiving a "thing" from one or the other perspective at will and in different sensory modalities; (3) the "spatiotemporality" within which my spontaneous locomotion takes place; (4) the functioning of association by similarity in perceptual apprehension, thanks to which I can have specific expectations for the "things" I encounter; etc. (Declerck 2019).

Among these elements of the primordial domain we can find the phenomena that ground the positing of others. If a unity of manifestations regularly correlated with my potentialities manifests a specific concordance with the experience of my own animate organism, this concordance may legitimate an initial bestowal of the meaning "animate organism." Specifically, because the unity is "over there" with respect to the "here" of my animate body, I cannot bestow the meaning "my animate organism," which would imply experiencing the unity as "here;" rather, the unity over there must be comprehended as an "animate organism other than myself" (Hua I, p. 148). Finally,

The experienced animate organism of another continues to prove itself as actually an animate organism, solely in its changing but incessantly harmonious "behavior." Such harmonious behavior (as having a physical side that indicates something psychic appresentatively) must present itself fulfillingly in original experience, and do so throughout the continuous change in behavior from phase to phase. (Hua I, p. 144; 1999, p. 114)

In sum, there is the experience of perceptual unities that let themselves be comprehended in light of the idea "animate organism," an idea that originates at first in the experience of my own body. When others are not present, there is the experience of a spatiotemporality that I can still assume to be one shared with others. These experiences verify the assumption intrinsic to the positing of intersubjectivity. Thus, the continuation of these experiences grounds such positing.

\subsection{Ultimately Fallible Evidence}

What is the status of the evidence that world-belief grounding exhibits? In some passages Husserl ascribes apodicticity to the world, but this should not confound us: what Husserl is saying — in most, at least, of these passages - is merely that any illusion concerning a worldly item requires the validity of the world with respect to which it is established as illusion (Hua III/1, p. 61). Yet the world has only a "relative apodicticity," not the absolute one of transcendental subjectivity (Hua VIII, pp. 397-406; Hua XXXIX, pp. 211-236).

Affirming the relative character of the world's apodicticity coincides with affirming the presumptive, and therefore fallible, nature of the evidence supporting the world-belief. Concordant world-experience so far is such that each of us can 
legitimately presume future experiential confirmation. However, nothing allows us to fix it in advance. This idea can be understood in terms of the facticity of world-experience.

World-experience is a fact, but the flux of my "retentions, impressions, and protentions" could be different. Specifically, it could become such that no sensory unity can ever be again apprehended as an "animate being other than myself" and that all expectations characterizing intersubjective transcendence are systematically disappointed. These includes the expectation for confirmation of the environment shared with others-e.g. the earth on which I believed we were located. Only transient sensory unities would come and go in my flux — not for a period that is intrinsically limited, as in a phenomenon of madness, but for the total flux ad infinitum (Majolino 2016).

Experiencing spatiotemporality as intersubjective entails bestowing a meaning that prescribes expectations for the total future flux. The pure possibility that the epistemologist is called to ponder is one where this bestowal of meaning is retained as partially verified in the past but then is disappointed ad infinitum and has therefore undergone a process of modalization up to a final stage of negation (Hua XI, pp. 25-30). Acknowledging this pure possibility is admitting that the world-belief is, in the last analysis, fallible. This is what Husserl does in texts spanning at least from 1913-1931 (Hua I, p. 57; Hua III/1, p. 104; Hua V, pp. 152-153; Hua VIII, pp. 44-69; Hua XVII, p. 258; Hua XXXVI, p. 181; Hua XLI, pp. 354-356). For Husserl, the ultimate fallibility of world-experience is a consequence of the general fallibility of experiential evidence (Hua VI, p. 270), but what is of interest in the present paper is only the application of fallibilism in the domain of world-belief grounding.

\section{Further Clarifications}

\subsection{From World-Belief to Naivete Suspension}

Once world-belief grounding has been realized, as described in the previous section, the epoché as world-belief suspension can be dropped because it has achieved its purpose (Hua VIII, p. 479; Hua XXIV, p. 215; Hua XXXIV, p. 245). However, the epoché can be maintained as having a different meaning in a different context. Specifically, it can be practiced as the suspension of natural naivete in the metaphysical context, where one reflectively endorses the world-belief and, on this basis, posits the body-intersubjectivity-world triad.

For Husserl, the path of transcendental philosophy entails a shift in the meaning of the epoché from world-belief suspension to suspension of natural naivete in the metaphysical context (Hua XXXIV, pp. 17-22; Hua XXXIV, pp. 59-61). The reason why world-belief grounding precedes metaphysics is simple: metaphysics posits a fundamental transcendent fact. If the evidence at the basis of this positing is not clarified, the positing suffers a philosophically unacceptable lack of critical selfexamination (Hua XXIV, p. 191; Hua XXX, p. 330). Yet the reverse is not the case: without metaphysics, world-belief grounding suffers no lack of self-examination. 


\subsection{OEITI as Presupposition}

Without OEITI as clarification of the world-belief, the radical epistemologist would not know what she is supposed to ground. Even worse, she could mistake the world-belief for the countersensical positing of absolute mind-independence, which would mean that she would be attempting to exhibit evidence for a belief for which there cannot be any. As discussed in 3.4, clarification is not endorsement: OEITI does not entail affirming the world's existence; it only explicates what is posited when the natural attitude posits it. For these reasons, OEITI is a presupposition of world-belief grounding, and this presupposition does not entail a circular reaffirmation of the world-belief. As Husserl puts it,

The question of grounding the existence of the world has a legitimate meaning, but only as grounding of the existence of a world that is constituted in immanence as intentional unity, an "ideal" unity with respect to immanence, and that is constantly anticipated, a world that is transcendent in this sense-but not as grounding of a mythology of things in themselves. Only on the basis of phenomenological-transcendental idealism have we the clear and countersense-free formulation of the question. (Hua XXXVI, pp. 181182)

\subsection{Transcendental-Metaphysical Epistemology $\neq$ Radical Epistemology}

In order to understand why only the transcendental reduction understood as reflection based on world-belief suspension can realize world-belief grounding, it is necessary to distinguish world-belief grounding from a kind of epistemology that can be carried out from within the transcendental-metaphysical context outlined above.

In the latter context, I endorse natural world-positing and affirm the existence of transcendental worldly subjects the world cannot exist without. I can also reflect on the entire domain of experience, with the proviso that I consider this domain and each item of it as belonging to a worldly subject (infinitely-intersubjectively verifiable). Thus, I can pursue the epistemological question of how transcendental worldly subjects can have beliefs that are justified by corresponding experiences. This question can apply to the world-belief as well.

However, the epistemology of the world-belief of worldly transcendental subjects is not world-belief grounding. In the context of metaphysical world-belief endorsement, I can clarify why a human being like myself has a justified world-belief, but I can never show why I am justified in positing a transcendent human being like myself in the first place. Since I reflect on transcendent phenomena and this reflection presupposes the world-belief, I cannot show how transcendent knowledge is at all possible, how a subject in general-or myself purely as experiencer, i.e. insofar as I am an "I' and nothing else" (Hua XIII, p. 441) - can legitimately posit something that infinitely transcends its (already actualized) experience. Conflating transcendental-metaphysical epistemology with radical epistemology (world-belief grounding) is a form of nonsensical circularity. 
In order to avoid nonsensical circularity, radical epistemology requires a firm grasp on the distinction between transcendence and immanence (Sects. 3.2, 7). Transcendence implies the assumption that world-experience is verifiable ad infinitum. Considering world-experience as an immanent phenomenon entails considering it as it has been actualized so far independently of any assumption on its verifiability in the further course of experience. Even the "empty intentions" characterizing world-experience so far and their correlates as emptily intended are actual or were actualized. The positing of transcendence with its predetermined horizon of nonactual(ized) experience is an actual phenomenon and is epistemically grounded by actual and actualized experience. Hence world-belief grounding requires considering transcendental constitution as an ongoing, never completed process, where there is an ineradicable distance between what is at each time actually realized and final completion. $^{2}$

In Husserl's own words, only "in the context of a radical justification"-i.e. the context of world-belief suspension- "the being of the world" is "in one performance both understood and justified" through "transcendental clarification" (Hua XXXIV, pp. 244-245). Radical justification requires illuminating the extent to which this "being" is actually known and potentially knowable (die Tragweite dieses Seins als erkannten und erkennbaren).

\subsection{Paths in Transcendental Philosophy}

In order to secure a solid understanding of Husserl's radical epistemology, it is necessary to distinguish it from Husserl's metaphysics but also to realize how both fit within the same transcendental philosophy. Thus, we shall examine two texts where both their distinction and their relation can be evinced.

In a passage discussing his own usage of the expression "exclusion of the world," Husserl asserts that "in a certain, well-understood manner" it is correct to say that the world "is no longer a theme for phenomenology" (Hua VIII, p. 432; 2019, p. 566). The correct way to understand world-exclusion talk is that radical epistemology requires excluding the existing world and worldly phenomena from its domain of investigation in order to avoid circular domain-shifting. Importantly, as we discussed in 11.2, this exclusion does not entail excluding the world as it has been presenting itself in experience, which is the crucial phenomenon for world-belief grounding. This reassertion of the legitimacy of world-exclusion talk is confirmed by Husserl's reliance on it in later texts (Hua I, p. 64; Hua V, pp. 145-146; Hua XXXIV, p. 20).

\footnotetext{
${ }^{2}$ In this regard, it is helpful to explicate Husserl's metaphor of the "lower natural I" (Sect. 9) through reference to a Cartesian plane. The "reflecting I," who has taken position above, looks down at natural life occurring horizontally between the "natural I" (left) and her meant world purely as meant (right). This world-directed life grows in time, represented by the vertical y-axis, where it finds its continuous confirmation. Indeed, world-experience entails the expectation of future verification along the y-axis. It would be a fatal metabasis if the "reflecting I" who is engaged in radical epistemology reversed her theoretical interest in the natural upwards direction.
} 
"But"-one should not neglect Husserl's "aber"-when one moves to the metaphysical context where transcendental phenomenology can function "as 'empirical' science of the transcendental, [and encompasses] all factical sciences of the factical world," then world-exclusion has clearly no place (Hua VIII p. 432; 2019, pp. 566-567). The shift to this metaphysical context is ratified as the positing of "universal subjectivity in its full universality" (p. 566), i.e. "inter-subjectivity [...] in the state of humanness or natural worldliness" (Hua VIII, p. 480; 2019, p. 600). That intersubjectivity is posited in "rightful validity" hints at the fact that, in Husserl's favorite progression, the shift does not occur independently of world-belief grounding (Hua VIII p. 432; 2019, p. 566).

A more articulated staging of this progression can be found in Text 21 in Hua XV, where Husserl proposes a "path of systematic descriptions" (p. 362). The path begins with reflection in the attitude of world-belief suspension: the positing of the world's existence belongs to my lived experience, but "is bracketed in my epoché" (Hua XV, p. 363). Having the transcendental other- "transcendental" means "worldexperiencing" here-as noematic correlate in the attitude of world-belief suspension does not mean having posited her existence (Hua XV, p. 364). Yet, although in this attitude I cannot assume that the total future course of experience would verify the positing of the other, I can still recognize this possibility, i.e. the possibility of the other's existence. At this point, Husserl asks the question that manifests his intention to reach the metaphysical context: how can this possibility become an actuality for me, and when does it have to become so (Hua VIII, pp. 364-365)?

In order to realize this shift to actuality, Husserl calls to mind-in the attitude of world-belief suspension-the epistemic ground of the world-belief: this is the "connection of motivation" of presenting experience legitimizing the positing of the unity transcending the plurality of experiences. Hence Husserl recalls that grounding transcendence is analogous to grounding the positing of the other, which is described as "a certainty that anticipates possible further fulfillments in my familiar capacity" (Hua XV, p. 365). The phenomenon of my familiar-i.e. already habitually actualized-capacity of achieving fulfillment in regard to the expectations intrinsic to the positing of the other is precisely what grounds such positing. Once this radical epistemological insight has been revived, Husserl can endorse the positing of transcendence from an illuminated philosophical perspective. From now on, the text makes explicit references to metaphysics (Hua XV, p. 366, p. 370) and presents the metaphysical position characterized in Sect. 4.

Although world-belief grounding is clearly not the main interest underlying the text, in text 21 we can see how Husserl has to summon up world-belief grounding before appropriating a metaphysical approach to (transcendent) actuality. Thus, Husserl can move flexibly from radical epistemology to the metaphysical context without disowning the demands of each. The difference between the demands of each context is particularly evident with regard to subjectivity. The metaphysical domain demands granting validity to the natural assumption concerning subjectivity, i.e. that it is a worldly being ideally amenable to infinite intersubjective verification. In contrast, world-belief grounding requires avoiding psychologistic circularity and, therefore, it demands that we refrain from granting validity to the natural assumption concerning subjectivity. 
In sum, the metaphysical context and the radical-epistemological context exclude each other, but they can be taken up one after the other as parts of a unitary transcendental philosophy. Indeed, there are also abstract transcendental-philosophical elements that present themselves in both contexts. One is OEITI, which is presupposed as clarification of the meaning of being both in the radical-epistemological and the metaphysical context. Another is the emphasis on facticity. The triad body-intersubjectivity-world is a necessity only in relation to empirical actuality, which is taken to be valid and in need of metaphysical explanation, but not in relation to actuality in general. The triad is a "fundamental fact." An index of facticity, as opposed to necessity, is the possibility of not being. Consistent with this, revealing the ultimate fallibility of the world-belief in radical epistemology implies exhibiting the possibility of the world's non-being. In Husserl's perspective, we cannot claim the world as something that is a priori owed to any experiencer. In this sense, we could borrow Zahavi's (2017, p. 180) words, inspired by Merleau-Ponty: "the world is [...] a gift."

\section{Conclusion}

Husserl invites us not to be afraid of the radicalism of transcendental inquiry (Hua VIII, pp. 481-482). There is no reason to fear that we may lose something of the natural attitude. The co-existence of body, others, and world is never called into doubt and continues to be posited in our natural life precisely while we take the radical-epistemological attitude to reflect upon it. Even more, it is presupposed from the start that this co-existence is evident. World-belief grounding is nothing else than the project of clarifying this evidence. It would be out of place to ask for philosophical arguments to secure our embodied, world-embedded, and intersubjective existence. Natural experience attests it in a way that is not actually possible for us to doubt (Hua XXIV, pp. 190-191; Hua XXVII, p. 170).

The epistemological contribution of the transcendental reduction consists in the coherent formulation and solution of the world-belief grounding problem. The problem is meaningful only if it is formulated as the project of clarifying the epistemic ground of the world-belief without circularly presupposing this belief and without shifting to worldly transcendencies. The problem is solved by recognizing that concordant world-experience legitimates the positing of the world's further verifiability. This solution includes identifying a non-intersubjective bedrock of experience without which world-experience would not be possible. In such substratum, I can ascertain the original constitution of the meaning "animate organism" in the experience of my own lived body, the persistent behavior of perceptual unities in a spatial position different from mine complying with the meaning "animate organism other than myself," and the experience of an environment consistent with the meaning "environment shared with others." These are the experiences that rationally ground the positing of intersubjectivity (11.4).

It goes without saying that this paper invites further work that should clarify in detail the features of the solution to world-belief grounding that have been outlined here in broad strokes. Nonetheless, some virtues of the Husserlian solution already emerge from our investigation. First, both the necessity and the viability of 
world-belief suspension are demonstrated in light of the general structure of critical examination (Sects. 6, 9). Second, contrary to appearances, world-belief suspension is revealed to be an essentially anti-Cartesian move. For consistent world-belief suspension requires becoming aware of Descartes' fundamental error: considering subjectivity as a worldly being while pursuing radical epistemology, i.e. transcendental psychologism (Sect. 8). Third, Husserl's discussion is nourished by a healthy aversion to pseudo-problems. With his emphasis on the notion of nonsensical domainshifting (metabasis), Husserl sides with authors like Wittgenstein, Quine, and Foucault in affirming that word-belief grounding is meaningless in the natural attitude (Sects. 7, 10).

Fourth, critical-hermeneutic awareness can be evinced in the distinction between grounding, a species of critical examination, and knowing: the former exhibits the hermeneutic circle as the locus of confirmation characterizing the latter (Sect. 6). From the radical-epistemological perspective, transcendental reflection is inclusive of all phenomena from past experience (body, language, intersubjectivity, tradition, etc.) that determine current thought and meaning-constitution (Sect. 11.3). Fifth, acknowledging the presumptivity of the world-belief, and thus the facticity intrinsic to its verification, extends fallibilism beyond usual boundaries (Sect. 11.5). Lastly, world-belief grounding is not just an epistemological vindication of natural world-belief. It contributes to realizing a comprehensive philosophy together with the emphasis on embodiment and intersubjectivity characteristic of Husserl's transcendental idealism. World-belief grounding demands such emphasis as part of the clarification of the meaning of being (OEITI) and prevents its replication at the metaphysical level (MEITI) from suffering a philosophically unacceptable lack of critical self-examination (Sects. 3, 4, 12.1-12.4).

Acknowledgements The final version of this paper has benefited from the comments made to previous versions by a number of colleagues in recent years. In particular, I am grateful for their comments to Tom Nenon, Shaun Gallagher, Antonio Zirión Quijano, Dan Zahavi, Andrea Staiti, Esteban Marín Ávila, Ignacio Quepons, Stefania Centrone, Paula Lorelle, Carmine Di Martino, Fariba Khalili, the editor Steven Crowell, and two anonymous reviewers. Open access funding provided by the University of Vienna.

Funding The funding was provided by Dirección General de Asuntos del Personal Académico, Universidad Nacional Autónoma de México (Grant Number: UNAM Post-doctoral Fellowship Program during the academic year 2017-2018) and by OeAD-GmbH (Grant Number: Ernst Mach Fellowship Program 2019-2020 at the University of Vienna).

Open Access This article is licensed under a Creative Commons Attribution 4.0 International License, which permits use, sharing, adaptation, distribution and reproduction in any medium or format, as long as you give appropriate credit to the original author(s) and the source, provide a link to the Creative Commons licence, and indicate if changes were made. The images or other third party material in this article are included in the article's Creative Commons licence, unless indicated otherwise in a credit line to the material. If material is not included in the article's Creative Commons licence and your intended use is not permitted by statutory regulation or exceeds the permitted use, you will need to obtain permission directly from the copyright holder. To view a copy of this licence, visit http://creativecommons.org/licen ses/by/4.0/. 


\section{References}

Berghofer, P. (2019). Husserl's noetics-Towards a phenomenological epistemology. Journal of the British Society for Phenomenology, 50(2), 120-138.

Declerck, G. (2019). Do we need others to perceive objects? Etudes phénoménologiques-Phenomenological Studies, 3, 191-220.

Drummond, J. J. (1990). Husserlian intentionality and non-foundational realism. Dordrecht: Kluwer.

Drummond, J. J. (2019). Review of Dan Zahavi, Husserl's legacy: Phenomenology, metaphysics, and transcendental philosophy. Husserl Studies, 35, 265-273.

Hua I. Husserl, E. (1973). Cartesianische Meditationen und Pariser Vorträge. S. Strasser (Ed.). The Hague: Martinus Nijhoff. Cartesian meditations D. Cairns (Trans.). The Hague: Martinus Nijhoff, 1999.

Hua II. Husserl, E. (1973). Die Idee der Phänomenologie. Fünf Vorlesungen. W. Biemel (Ed.). Den Haag: Kluwer Academic Publishers. The idea of phenomenology. L. Hardy (Trans.). The Hague: Martinus Nijhoff, 1999.

Hua III/1, 2. Husserl, E. (1976). Ideen zu einer reinen Phänomenologie und phänomenologischen Philosophie. Erstes Buch. K. Schuhmann (Ed.). Den Haag: Martinus Nijhoff; Ideas for a pure phenomenology and phenomenological philosophy. First book. F. Kersten (Trans.). The Hague; Martinus Nijhoff, 1982.

Hua IV. Husserl, E. (1952). Ideen zu einer reinen Phänomenologie und phänomenologischen Philosophie. Zweites Buch. Den Haag: Martinus Nijhoff.

Hua V. Husserl, E. (1971). Ideen zu einer reinen Phänomenologie und phänomenologischen Philosophie. Drittes Buch. Den Haag: Martinus Nijhoff.

Hua VI. Husserl, E. (1976). Die Krisis der europäischen Wissenschaften und die transzendentale Phänomenologie. W. Biemel (Ed.). The Hague: Nijhoff; The crisis of European sciences and transcendental phenomenology. D. Carr (Trans.). Evanston: Northwestern University Press, 1970.

Hua VII. Husserl, E. (1956) Erste Philosophie I (1923/24). R. Boehm (Ed.). The Hague: Martinus Nijhoff.

Hua VIII. Husserl, E. (1959). Erste Philosophie II (1923-24). Den Haag: Martinus Nijhoff; First philosophy. Lectures 1923/24 and related texts from the manuscripts (1920-1925). S. Luft and T. M. Naberhaus (Trans.). Dordrecht: Springer, 2019.

Hua IX. Husserl, E. (1962). Phänomenologische Psychologie. Den Haag: Martinus Nijhof; Psychological and transcendental phenomenology and the confrontation with Heidegger (1927-1931). T. Sheehan and R. E. Palmer (Trans.). Dordrecht: Kluwer Academic Publishers, 1997.

Hua X. Husserl, E. (1966). Zur Phänomenologie des inneren Zeitbewußtseins (1893-1917). Den Haag: Martinus Nijhoff.

Hua XI. Husserl, E. (1966). Analysen zur passiven Synthesis: Aus Vorlesungs- und Forschungsmanuskripten 1918-1926. The Hague: Martinus Nijhoff.

Hua XIII. Husserl, E. (1973). Zur Phänomenologie der Intersubjektivität I. Den Haag: Martinus Nijhoff. The basic problems of phenomenology: From the lectures, winter semester, 1910-1911. I. Farin and J. G. Hart (Trans.). Springer, Dordrecht, 2006.

Hua XV. Husserl, E. (1973). Zur Phänomenologie der Intersubjektivität III. Den Haag: Martinus Nijhoff.

Hua XVII. Husserl, E. (1974). Formale und transzendentale Logik. P. Janssen (Ed.). The Hague: Nijhoff. Formal and transcendental logic. D. Cairns (Trans.). The Hague: Martinus Nijhoff, 1969.

Hua XXIV. Husserl, E. (1984). Einleitung in die Logik und Erkenntnistheorie. U. Melle (Ed.). Dordrecht: Nijhoff; Introduction to logic and theory of knowledge. C. O. Hill (Trans.). Dordrecht: Springer, 2008.

Hua XXVII. Husserl, E. (1989). Aufsätze und Vorträge (1922-1937). T. Nenon and H. R. Sepp (Eds.). Dordrecht: Kluwer Academic.

Hua XXX. Husserl, E. (1996). Logik und allgemeine Wissenschaftstheorie. U. Panzer (Ed.). Dordrecht: Kluwer.

Hua XXXII. Husserl, E. (2001). Natur und Geist: Vorlesungen Sommersemester 1927. M. Weiler (Ed.). Dordrecht: Kluwer Academic.

Hua XXXIV. Husserl, E. (2002). Zur phänomenologischen Reduktion. Texte aus dem Nachlass (1926-1935). Dordrecht: Kluwer Academic Publishers.

Hua XXXIX. Husserl, E. (2008). Die Lebenswelt. Auslegungen der vorgegebenen Welt und ihrer Konstitution. Texte aus dem Nachlass (1916-1937). R. Sowa (Ed.). Dordrecht: Springer.

Hua XXXVI. Husserl, E. (2003). Transzendentaler Idealismus. Texte aus dem Nachlass (1908-1921). Dordrecht: Kluwer Academic Publishers.

Hua XLI. Husserl, E. (2012). Zur Lehre vom Wesen und zur Methode der eidetischen Variation. Texte aus dem Nachlass (1891-1935). D. Fonfara (Ed.). Dordrecht: Springer. 
Lohmar, D. (2012). Ego and arch-ego in husserlian phenomenology. In R. Breeur \& U. Melle (Eds.), Life, subjectivity, art: Essays in honor of Rudolf Bernet (pp. 277-302). Dordrecht: Springer.

Majolino, C. (2016). "Until the end of the world": Eidetic variation and absolute being of consciousness-A reconsideration. Research in Phenomenology, 46, 157-183.

Rinofner-Kreidl, S. (2004). What is wrong with naturalizing epistemology? A phenomenologist's reply. In R. Feist (Ed.), Husserl and the sciences. Selected perspectives (pp. 41-68). Ottawa: Ottawa University Press.

Zahavi, D. (2003). Husserl's phenomenology. Stanford: Stanford University Press.

Zahavi, D. (2017). Husserl's legacy: Phenomenology, metaphysics, and transcendental philosophy. Oxford: Oxford University Press.

Publisher's Note Springer Nature remains neutral with regard to jurisdictional claims in published maps and institutional affiliations. 